\title{
Clinical epidemiology of Alzheimer's disease: assessing sex and gender differences
}

This article was published in the following Dove Press journal:

Clinical Epidemiology

8 January 2014

Number of times this article has been viewed

\author{
Michelle M Mielke ${ }^{1,2}$ \\ Prashanthi Vemuri ${ }^{3}$ \\ Walter A Rocca ${ }^{1,2}$ \\ 'Department of Health Sciences \\ Research, ${ }^{2}$ Department of Neurology, \\ ${ }^{3}$ Department of Radiology, Mayo \\ Clinic, Rochester, MN, USA
}

\begin{abstract}
With the aging of the population, the burden of Alzheimer's disease (AD) is rapidly expanding. More than 5 million people in the US alone are affected with AD and this number is expected to triple by 2050. While men may have a higher risk of mild cognitive impairment (MCI), an intermediate stage between normal aging and dementia, women are disproportionally affected with AD. One explanation is that men may die of competing causes of death earlier in life, so that only the most resilient men may survive to older ages. However, many other factors should also be considered to explain the sex differences. In this review, we discuss the differences observed in men versus women in the incidence and prevalence of MCI and $\mathrm{AD}$, in the structure and function of the brain, and in the sex-specific and gender-specific risk and protective factors for AD. In medical research, sex refers to biological differences such as chromosomal differences (eg, XX versus XY chromosomes), gonadal differences, or hormonal differences. In contrast, gender refers to psychosocial and cultural differences between men and women (eg, access to education and occupation). Both factors play an important role in the development and progression of diseases, including AD. Understanding both sex- and genderspecific risk and protective factors for $\mathrm{AD}$ is critical for developing individualized interventions for the prevention and treatment of AD.
\end{abstract}

Keywords: Alzheimer's disease, dementia, sex, gender, risk factors, dimorphic medicine

\section{Introduction}

Alzheimer's disease (AD) is the most prevalent type of dementia, comprising about $60 \%-70 \%$ of all dementia cases. ${ }^{1}$ Beta-amyloid plaques, neurofibrillary tangles, and neurodegeneration are the hallmark pathologic characteristics of AD. Clinically, AD is a progressive disorder characterized by loss of memory and overall cognitive functioning and by behavioral symptoms such as apathy, depression, and anxiety; vocabulary and crystallized abilities are preserved. The burden of AD is high, with more than 5 million people currently affected in the US alone. Presently, one in nine people aged 65 and older has AD and more than one in three people aged 85 and older are affected. ${ }^{2}$ With the increasing age of the population, it is estimated that 14-16 million Americans will be diagnosed with the disease by 2050 unless new treatments to prevent or delay the onset of AD are identified. ${ }^{3,4}$ Women are disproportionally affected by AD; they are more likely to become caregivers to AD patients, and are also more likely to develop $\mathrm{AD} .{ }^{2}$ In contrast, some studies suggest that men are at greater risk of developing mild cognitive impairment (MCI), a state between the normal cognitive changes associated with aging and early dementia. ${ }^{5,6}$ Sex-related differences in the rate of progression after a diagnosis of $\mathrm{AD}$ and in the response to treatments have also been reported.
Correspondence: Michelle M Mielke Department of Health Sciences Research, Mayo Clinic, 200 First Street SW, Rochester, MN, USA 55905

$\mathrm{Tel}+\mathrm{I} 5072845545$

Fax +| 507284 I5I6

Email mielke.michelle@mayo.edu 
In the present review, we will first summarize sex differences in cognitive aging, in the prevalence and incidence of MCI and $\mathrm{AD}$, and in the rate of progression after an $\mathrm{AD}$ diagnosis. We will then discuss sex-specific differences in the neuroimaging measures used to study AD. Lastly, we will review potential reasons for the described differences between men and women considering factors both related to biology (sex) and to society and culture (gender). ${ }^{7-9}$

\section{Sex versus gender}

An Institute of Medicine report published in 2001 concluded that "being male or female is an important fundamental variable that should be considered when designing and analyzing basic and clinical research."7 In medical research, sex refers to biological differences such as chromosomal (eg, XX versus XY chromosomes), gonadal, or hormonal differences. In contrast, gender refers to psychosocial and cultural differences between men and women (eg, access to education and occupation). ${ }^{10}$ Both factors play an important role in the development and progression of diseases, including AD. ${ }^{8,9}$ In this review, potential sex and gender differences that may influence the difference in prevalence and incidence rates of $\mathrm{MCI}$ and AD among men and women will be discussed.

\section{Sex differences in cognitive aging, in the prevalence and incidence of $\mathrm{MCl}$ and $A D$, and in the rate of progression after a diagnosis of AD Cognitive aging}

The shrinking of the brain and expansion of the ventricles is part of the natural maturational process of the brain during normal aging. Longitudinal studies that have used "normal" cognitive status as an inclusion criterion have found that even "normal" aging may contribute to subtle declines in cognitive functioning. ${ }^{11,12}$ There are significant sex differences in the normal aging process. ${ }^{13}$ The most consistent cross-sectional difference at all ages is that women perform better on verbal memory tasks and men perform better on visuospatial tasks. ${ }^{14-16}$ However, longitudinal studies have shown inconsistent sex differences, either reporting steeper annual rates of cognitive decline in men, ${ }^{17}$ women, ${ }^{14}$ or no sex differences. ${ }^{18}$ One of the major factors causing these inconsistent findings may be the cognitive reserve profiles (discussed later) of specific cohorts (eg, the Lothian Birth cohorts of 1921 and 1936). ${ }^{19}$

The trajectory of cognitive decline due to ongoing pathological insults to the brain ("pathological aging") has been shown to deviate from the normal aging process. There is significant accelerated decline in cognitive functioning and brain volume loss years before the onset of MCI or dementia. ${ }^{20-23}$ However, there have been no systematic studies of sex differences in the cognitive decline prior to onset of clinical symptoms (ie, preclinical stages of the disease).

\section{$\mathrm{MCl}$}

MCI is considered an intermediate state between the cognitive changes associated with aging and mild dementia, particularly of the Alzheimer type. ${ }^{24-26}$ Indeed, the risk of dementia is higher in persons with MCI compared to cognitively normal individuals. ${ }^{27-30}$ The prevalence of MCI in persons older than 65 years of age ranges from $10 \%$ to $20 \%$, depending on the population studied and on the diagnostic criteria utilized. ${ }^{6,27,28,31-34}$ Some studies suggest a higher prevalence of MCI in men, ${ }^{6,35,36}$ while others suggest either a higher prevalence in women ${ }^{33,37}$ or no sex difference. ${ }^{38-40}$ The incidence rate of MCI has been estimated to be about $1 \%-4 \%$ per year in cognitively normal individuals aged 65 and older. ${ }^{27,40-42}$ Some studies examining the incidence of MCI also report that there may be sex differences, but reports vary based on the study design, diagnostic criteria, and age distribution of the sample. In general, women have a higher incidence of MCI at older ages. Men consistently have a higher incidence of the non-amnestic type of MCI. ${ }^{42,43}$ Amnestic MCI is defined as cognitive impairment that includes the memory domain whereas non-amnestic MCI refers to impairment in other domains (eg, executive functioning, visuospatial, language), but no impairment in memory. While amnestic MCI is considered prodromal for $\mathrm{AD}$, non-amnestic MCI is considered prodromal for non-AD dementias, such as vascular dementia. ${ }^{25}$

\section{$A D$}

The prevalence of AD is significantly higher in women compared to men. Recent estimates suggest that almost two-thirds of the individuals diagnosed with $\mathrm{AD}$ are women. ${ }^{3} \mathrm{~A}$ reason for the higher prevalence among women may be that they live longer, on average, than men. ${ }^{44,45}$ By contrast, incidence studies examining sex differences in AD are equivocal. The majority of studies conducted in the US have not observed sex differences in the rates of developing AD. ${ }^{46-52}$ In contrast to these studies, the Cache County Study (Cache County, UT, USA), did report a higher incidence of AD in men than women until age 78, after which women had a higher incidence than men. ${ }^{53}$ Similarly, the Mayo Clinic Study of Aging recently reported that the rate of progression from 
MCI to AD was similar in men and women aged 70-79, but higher in women than men after age $80 .{ }^{54}$ Consistent with these last two studies, most studies from European ${ }^{55-59}$ and Asian ${ }^{60,61}$ populations have also observed a higher incidence in women after the age of 80-85 years.

The reasons for these disparities across studies and geographic regions are not clear. Discrepancies could be due to the use of different diagnostic criteria for $\mathrm{AD}$ versus other forms of dementia, such as vascular dementia or Lewy body dementia. The differences may also be due to small sample sizes at the upper range of the age distribution, resulting in unstable estimates. Finally, some differences across Europe, Asia, and North America may be due to social, cultural, and historical events. For example, the impact of World War II and the following Cold War era have been very different across continents. Some of these historical events may have affected men and women differently. Notably, a metaanalysis of 13 studies of populations in the US, Europe, and Asia did show that women were at a significantly greater risk of developing $\mathrm{AD}$, but not other dementias. ${ }^{62}$ Interestingly, women also have a faster rate of cognitive and functional decline after a diagnosis of AD. ${ }^{63,64}$

\section{Sex differences in neuroimaging measures of brain reserve: structure and function}

The concept of brain reserve posits that subjects with higher reserve have a greater capacity to cope with pathological insults than those with low reserve, and that these individual differences in reserve mechanisms help explain why cognitive decline may be initiated at different times in relation to the onset of pathology for each individual. Specifically, the concept of brain reserve stemmed from the observation by Katzman et al that subjects with larger brains have greater capacity to withstand more pathology at the same level of cognitive performance. ${ }^{65}$ Cognitive reserve is discussed later in the review.

\section{Structure}

The most striking difference between the brain anatomy of men and women is the larger head size and cerebral brain volume in men $(\sim 10 \%){ }^{66}$ Therefore, one would expect men to be able to withstand more pathology compared to women. This hypothesis was supported by an autopsy study that found that women had significantly higher odds of a clinical diagnosis of $\mathrm{AD}$ at the same level of pathology ${ }^{67}$ While overall larger head sizes may suggest larger brain reserve in men, studies have consistently shown faster age-associated brain volume decline in men compared to women in cognitively normal individuals. ${ }^{68-71}$ However, in patients with MCI and AD, brain volumes have been found to decline faster in women than men, supporting the evidence of faster progression of women from MCI to AD. ${ }^{72}$ Thus, even after considering difference in head size, sexual dimorphism in the brain anatomy exists. ${ }^{66,73-75}$ For example, women typically have a higher percentage of grey matter in several brain regions, whereas men have a higher percentage of white matter. ${ }^{76}$ While many of these differences are likely due to sex chromosomes and sex hormones, ${ }^{77-79}$ the exact mechanism through which sex hormones influence brain structures is still poorly understood. Notably, one major flaw of the studies examining changes in brain structure with age has been the modeling of brain volume loss over the life span without taking into account hormonal changes in men and women over time.

\section{Function}

Functional imaging measures such as ${ }^{18} \mathrm{~F}$-fluorodeoxyglucose positron emission tomography (FDG-PET) for measuring metabolism and resting state functional magnetic resonance imaging for measuring brain connectivity have shown significant differences between men and women. ${ }^{76,80}$ Typically, cerebral blood flow and connectivity have been found to be higher in women in the parietal association cortices and higher for men in the visual and motor cortices, ${ }^{81,82}$ providing evidence for brain function and behavior differences between the sexes. Several imaging studies have shown that sex differences in the brain circuitry contribute to significant performance differences on specific cognitive tasks; for example, men perform better on visually oriented tasks. In the context of cerebral metabolic deficits associated with cognitive impairment in dementia, two studies have shown that men have more pronounced cerebral metabolic deficits compared to women at the same level of cognitive impairment, suggesting that the greater brain reserve in men may be helping them withstand more pathology than women at the same level of dementia severity. ${ }^{83,84}$ Given the current hypothesis that regions of high connectivity in the brain harbor amyloid deposition, ${ }^{85}$ there is clearly a need to investigate sex differences in the pathological cascade of AD.

\section{Biological explanations for the sex differences Genetics}

While many studies have examined and reported the relationship (or lack of) between numerous genes and single-nucleotide polymorphisms (SNPs) and risk of $\mathrm{AD}$, 
few studies have specifically examined whether the relationships vary by sex. One reason for this is the high number of individuals needed for genetic analyses, and lack of power to examine sex differences, particularly for genome-wide association studies. As a result, studies adjust for sex rather than stratify by sex, or examine interactions with sex. ${ }^{79}$ The identification of the different genetic processes that may affect the risk of $\mathrm{MCI}$ and $\mathrm{AD}$ in men and women is imperative for individualized preventive and treatment plans.

The $\varepsilon 4$ allele of the apolipoprotein $\varepsilon$ (APOE) gene is the strongest known genetic risk factor for late-onset $\mathrm{AD}^{86,87}$ Compared to non-carriers, heterozygous carriers of one $\varepsilon 4$ allele are 3-4 times more likely to develop $\mathrm{AD}$, whereas the risk for homozygous carriers is even higher. ${ }^{87,88}$ The APOE $\varepsilon 4$ allele is specifically associated with an earlier age of onset of $\mathrm{AD}{ }^{89}$ The majority of studies, including a large meta-analysis of 8,607 controls and 5,930 AD cases,${ }^{90}$ have reported that the effects of the $\varepsilon 4$ genotype are more pronounced in women than in men. ${ }^{90}$ Three studies reported that women with one $\varepsilon 4$ allele had about a four-fold risk of $\mathrm{AD}$, whereas men with one $\varepsilon 4$ allele showed little increased risk. ${ }^{90-92}$ The APOE $\varepsilon 4$ allele also has a greater deleterious effect on hippocampal pathology, functional connectivity changes in the default mode network, cortical thickness, and memory performance in women compared with men at different stages of AD. ${ }^{93-95}$ Additionally, a large autopsy study found that amyloid plaque and neurofibrillary tangle pathology was greatest among women who were $\varepsilon 4$ carriers. ${ }^{96}$

Other genes and SNPs have also been shown to increase risk and progression of $\mathrm{AD}$ in one sex, but not the other. A large study consisting of 16 research centers worldwide (including 4,711 patients and 4,537 controls) reported that the Met66 allele of Brain Derived Neurotrophic Factor (BDNF) gene, which reduces the transport of BDNF, is associated with an increased risk of $\mathrm{AD}$ in women (odds ratio $=1.14$, $95 \%$ confidence interval $1.05-1.24, P=0.002$ ), but not in men. ${ }^{97}$ This finding is biologically plausible since estrogen plays an important role in the expression of BDNF.98 Postmenopausal women with the MET66 allele would therefore have both reduced transport and expression of BDNF, thus causing an increased risk of AD.

SNPs found to pose a risk of AD among men, but not women, include a SNP (rs688) of the low-density lipoprotein receptor and functional apolipoprotein E receptor, ${ }^{99}$ the rs $17571 \mathrm{SNP}$ of the lysosomal protease cathepsin $\mathrm{D},{ }^{100} \mathrm{SOS} 2$ (involved in signal transduction pathways, including insulin signaling), and PCK1 (catalyzes the first step in hepatic gluconeogenesis). ${ }^{101}$ Interestingly, a few SNPs have also been found to have an opposite predictive value for women compared with men. A diabetes-related gene, the $G$ allele of NSP65 of the peroxisome proliferators-activated receptors gamma was associated with a significantly increased odds of $\mathrm{AD}$ in men, but a reduced odds in women. ${ }^{101}$ In contrast, the $219 \mathrm{~K}$ allele of the ATP Binding Cassette Transporter 1 ( $A B C A 1)$ gene had a 1.75-fold increased risk of developing $\mathrm{AD}$ in women, but was found to be protective in men. ${ }^{102}$

The biological explanations for these sex differences are not fully understood, in part because the physiological effects of many of the genetic polymorphisms have not been completely determined. Most studies finding sex differences link the association to sex hormone levels. For example, some of the physiological benefits of estrogen have been linked to ABCA1-mediated pathways. ${ }^{103}$ However, there could also be gene-gene interactions (epistasis) of genes on an autosomal chromosome with genes on chromosome $\mathrm{X}$ or $\mathrm{Y}$. With the continued observation of sex differences in the risk of $\mathrm{AD}$ for identified SNPs, better understanding of the resulting physiological changes that contribute to the sex difference is needed.

\section{Hormones}

Gonadal hormones act as critical neurotrophic factors in the perinatal period and throughout the lifespan. Both hormones and genetic differences (ie, $\mathrm{X}$ and $\mathrm{Y}$ chromosomes) ${ }^{79}$ contribute to the physiological mechanisms underlying sexual dimorphism of the brain, including neurogenesis, axon guidance, synaptogenesis, and neurovascular development. ${ }^{104}$ Following menopause, women experience relatively rapid loss of the ovarian sex hormones 17 beta-estradiol and progesterone. A bilateral oophorectomy prior to menopause causes an abrupt deficiency of estrogen, progesterone, testosterone, and a disruption of the hypothalamic-pituitaryovarian axis. ${ }^{105,106}$ Men also experience significant declines in testosterone levels with age, but these declines are more gradual. Bioavailable testosterone declines $2 \%-3 \%$ per year after the age of $30 .{ }^{107}$ Because testosterone can be metabolized to estrogen, men do not have the severe estrogen loss, even in late-life, that is experienced by women after menopause or abruptly after a bilateral oophorectomy prior to menopause.

Animal and cellular models have consistently shown the neuroprotective effects of estrogen which include: improving synapse formation on hippocampal dendritic spines, ${ }^{108,109}$ maintaining hippocampal function during aging; ${ }^{110}$ improving cerebral blood flow and glucose metabolism, ${ }^{111}$ increasing choline acetyltransferase activity in the basal forebrain and hippocampus (choline acetyltransferase is involved in the 
synthesis of acetylcholine, a neurotransmitter reduced in $\mathrm{AD}$ and implicated in memory function), ${ }^{12,113}$ reducing the aggregation of amyloid-beta and associated neurotoxicity, ${ }^{114,115}$ and preventing mitochondrial damage. ${ }^{116}$ Despite the apparent benefits in animal and cellular models, the impact of estrogen loss (due to natural menopause or surgically induced) and of hormone replacement therapy (HRT), on the risk of $\mathrm{AD}$ in women remains controversial. To date, observational studies generally report reduced risks of AD in women who initiate HRT within a short period (typically $<3$ years) after natural menopause and after oophorectomy performed prior to menopause. ${ }^{105,117-122}$ For example, the Mayo Clinic Cohort Study of Oophorectomy and Aging showed an almost doubled risk of dementia in women who underwent bilateral oophorectomy before menopause. ${ }^{123}$ However, women who initiated HRT after the bilateral oophorectomy, and continued utilizing HRT at least until the age of natural menopause (approximately 51 years), did not experience an increased risk of AD. ${ }^{123}$ In contrast to these studies showing a beneficial effect of estrogen use, the Women's Health Initiative Memory Study (WHIMS), ${ }^{124}$ a large randomized clinical trial of HRT, reported a two-fold increased risk of dementia in women randomized to HRT after age 65 years. One explanation for the differences between observational studies and clinical trials is that observational findings could be the result of confounding. Women who use HRT typically have a higher socioeconomic status, higher education, and/or better health and therefore may be at lower risk of AD. However, another possibility is the timing of the estrogen therapy. ${ }^{106,125}$

Observational studies show that the use of HRT, when initiated around the time of menopause but not years after, reduces the risk of AD. ${ }^{105,117-122}$ In the Cache County Study, women who initiated HRT within 5 years of menopause had a $30 \%$ lower risk of $\mathrm{AD}$ compared to women who reported no use of HRT. However, women who began hormone therapy more than 5 years after menopause did not have a lowered risk. In fact, those who started hormone use when they were 65 years or older had almost a two-fold increased risk. ${ }^{122}$ Similarly, in both the Multi-Institutional Research on Alzheimer Genetic Epidemiology (MIRAGE) study and in the Northern California Kaiser Permanente study, initiation of HRT in mid-life was associated with reduced risk of AD, whereas initiation of HRT several years after menopause was associated with an increased risk. ${ }^{120,121}$

In light of the observational results suggesting that the initiation of estrogen in the immediate years after menopause is protective, whereas later administration increases AD risk, the WHIMS $^{124}$ trial results are not surprising. WHIMS subjects were aged 65-79 years old at baseline. Thus, HRT was initiated 10-20 years after the onset of natural menopause.

There are two ongoing hypotheses for the lack of benefit, or even detrimental effects, when estrogen is initiated years after menopause or bilateral oophorectomy. The first, "window of opportunity," hypothesis is based on the mechanistic findings that long-term estrogen depletion (LTED) can cause decreased levels of estrogen receptor (ER)-alpha, in the CA1 region of the hippocampus, a highly responsive region to estrogen therapy, resulting in cognitive enhancement and neuroprotection. ${ }^{126}$ Therefore, the initiation of estrogen after LTED, when ER-alpha receptors are already downregulated, does not result in the neuroprotective benefits of estrogen. The second, "healthy cell bias of estrogen benefit," hypothesis suggests that estrogen only yields neuroprotective benefits when applied to healthy neurons. ${ }^{127}$ Neurons with damaged mitochondria, a feature of aging, will not benefit, and estrogen may even be detrimental under these conditions. It is likely that both hypotheses contribute to differential benefits of estrogen when initiated peri-menopausal compared to after LTED.

\section{Social explanation for the gender differences}

In addition to several biological explanations for the observed sex differences in the prevalence and incidence of MCI and dementia, the effects of sociocultural aspects, ie, gender differences, should also be studied. Gender refers to the cultural and psychosocial factors that impact our identity and modify our risk of disease via health perception, risk behavior, social and work-related stressors, personal and societal perceptions of men's and women's role, patientdoctor relationships, and adherence to therapy. ${ }^{10,128}$ Specific factors related to gender identity that may contribute to the risk of $\mathrm{AD}$ include education, occupation, diet and exercise, and smoking and drinking behaviors. Gender is also strongly linked with the concept of cognitive reserve such that a higher education/occupation and greater engagement in cognitive activities provides higher reserve against disease and results in varying cognitive aging trajectories among individuals. ${ }^{128,129}$ In this section, we discuss gender-related risk and protective factors for $\mathrm{AD}$. All of these factors can be tied to the concept of cognitive reserve as proposed by Stern. ${ }^{130}$ This theory posits that subjects with higher cognitive reserve (eg, higher education, better diet, or less stress) may have a greater capacity to cope with pathological insults to the brain, or that it may take longer for them to reach the threshold of dementia detection. Thus, individuals with 
high cognitive reserve would be less likely to display the cognitive symptoms associated with dementia compared to individuals with the same pathology and low cognitive reserve. ${ }^{131,132}$

\section{Intellectual lifestyle: education, occupation, and cognitive activity}

Low education and low occupational history (eg, unskilled versus skilled worker) have repeatedly been associated with either a higher prevalence ${ }^{133-137}$ or incidence of AD. ${ }^{138-141}$ Cognitive activities have been shown to reduce the risk of dementia in the elderly. ${ }^{142,143}$ Intellectual lifestyle (education, occupation, and current cognitive activity) explains more than $10 \%$ of the variance in an individual's cognitive performance. ${ }^{131}$ Innate cognitive ability is also important, and can lead to higher education and better occupation. Indeed, low childhood mental ability and IQ is associated with lower cognitive ability in late-life, ${ }^{144}$ with an increased risk of dementia, ${ }^{145}$ and with increased mortality. ${ }^{146}$

Recent Pittsburgh compound B positron emission tomography (PiB-PET) and FDG-PET imaging studies have also shown that subjects with higher education or occupational engagement have more pathological changes when compared to subjects with lower education at the same level of cognitive performance (ie, they have greater brain reserve). ${ }^{147-150}$ The mechanism by which low education and occupation are thought to increase risk of $\mathrm{AD}$ is by lowering cognitive reserve. A longitudinal study that followed 9,000 people semi-annually for 15 years found that the main effect of education was to increase the baseline cognitive performance of individuals. ${ }^{151}$ Thus, subjects with higher education take longer to reach the dementia threshold. Sex differences in cognitive reserve and risk factors will further bias studies by causing different thresholds for detection of disease.

In the past century men have had more opportunities for higher education and higher occupational attainment than women. This is particularly true for individuals aged 70 and older who are now at greatest risk of developing AD, suggesting a higher education/occupation related reserve in men. In contrast, women generally engage in more cognitive activities such as reading books, arts and crafts, group, and social activities. While these cognitive activities impact reserve, the effect is much less than the impact of education and occupation. ${ }^{131}$

Indeed, differential age, period, and cohort effects in educational and occupational attainment may play particularly important roles for late-life cognitive trajectories and risk of AD. The Seattle Longitudinal Study showed that individuals born in later (1914-1948) versus early (1886-1913) cohorts have better cognitive performance at the age of 70 years, and also slower rates of cognitive decline. ${ }^{152,153}$ Notably, the differences between the younger and older cohorts in cognitive gains were much greater for women than men. This research highlights the importance of gender-specific societal changes in intellectual lifestyle over time by cohort and specific historical periods (eg, during versus after World War II), and its subsequent impact on cognitive aging trajectories and risk of AD.

At the most recent census, the educational attainment in the US was higher in women than men, ${ }^{154}$ and there also has been a dramatic shift in occupational engagement due to changing gender roles. For example, men and women have experienced different access to education and occupation in North America compared to Europe and Asia in the early part of this century. These gender-related differences may explain the observed geographic differences in the prevalence and incidence of AD that are described above. ${ }^{46-61}$ Indeed, it is possible that with greater educational and occupational attainment in women, the sex differences will diminish. The changing trends of intellectual lifestyles in men and women may contribute to changing epidemiologic patterns for $\mathrm{AD}$ and dementia across countries and over time.

\section{Exercise}

Gender roles can affect exercise participation as parenthood and marital status have been shown to be significantly related to whether women exercise. ${ }^{155}$ Several studies suggest that exercise and cardiorespiratory fitness are associated with a reduced risk of MCI and $\mathrm{AD}^{156-160}$ and with a slower rate of decline after a diagnosis of AD. ${ }^{161}$ While women are thought to be more "health-seeking" than men, it has been estimated that American women tend to get less exercise than men over the lifespan. ${ }^{162}$ Studies on sex differences in exercise patterns and risk of AD are ambiguous. Some studies suggest that exercise lowers the risk of cognitive decline and AD more in women than men. ${ }^{163,164}$ In contrast, another study suggested that women who exercise tend to receive less of a protective effect than men. ${ }^{165}$ These conflicting results may be due to the stage of life in which exercise is measured because most studies have measured self-reported physical activity in late-life. One study of over 9,000 women collected selfreported information on physical activity when the women were in their teens, age 30, age 50, and in later-life. ${ }^{158}$ Physical activity at all time points was associated with a reduced risk of cognitive impairment in late-life. However, physical activity in the teenage years was associated with the greatest 
reduction in risk. Women who were not active as teenagers, but who were physically active at age 30 and 50, also had a reduced risk, but not as much as those who were active as teenagers. Further, among women who were physically active as teenagers, late-life physical activity did not appear to further reduce the risk of cognitive impairment, suggesting that early activity, when the brain is developing, may be most important.

The benefits of teen activity on late-life cognition are likely multifactorial. Teens who are active have better cognitive performance. ${ }^{166}$ Youth physical activity may contribute to a cognitive reserve, similar to the effects of education, which would therefore have long-term effects on cognition. ${ }^{167}$ Physical inactivity in the teenage years is also associated with obesity and diabetes; ${ }^{168}$ both are risk factors for AD. ${ }^{169}$ Physical activity and exercise are much more strongly encouraged for girls and teenage women now compared to the early- and mid-20th century; time will determine the impact that this trend may have on the sex difference in the prevalence of AD. Notably, while there is increasing focus on exercise, overall lifestyle is becoming more sedentary. Low activity throughout the day may be more beneficial than 30 minutes of moderate physical activity combined with 10 hours of sedentary behavior. Little research to date has focused on sex differences in sedentary behavior and how these differences may relate to risk of AD.

\section{Smoking}

Acetylcholine is a neurotransmitter that is decreased in Alzheimer's patients. Indeed, the current US Food and Drug Administration-approved medications for AD primarily focus on inhibiting the degradation of acetylcholine. Nicotinic acetylcholine receptors are especially reduced in AD. Therefore, it was hypothesized that nicotine could be used to prevent or delay the progression of $\mathrm{AD}$, and that smoking may be associated with a reduced risk of AD. Indeed, nicotine has been shown to increase cognitive performance in both animals and human smokers. ${ }^{170}$ However, the results of clinical trials examining the use of a nicotine patch in $\mathrm{AD}$ patients have been mixed with some studies showing reduced cognitive decline, ${ }^{171}$ and others showing no beneficial effect. ${ }^{172}$ Larger studies are ongoing. Although it is possible that nicotine could be beneficial for $\mathrm{AD}$, cigarette smoking contains several other toxins, has carcinogenic effects, is a known risk factor for cardiovascular and pulmonary disease, and therefore may increase the risk of AD. Additionally, many smokers also drink, and the interaction between cigarette smoking and heavy alcohol use may be especially detrimental for cognition. ${ }^{173} \mathrm{~A}$ recent study suggests a strong interaction between smoking and alcohol use in predicting rate of cognitive decline, such that cigarette smokers who were heavy alcohol users had significantly faster rates of decline than smokers who were moderate alcohol users. ${ }^{173}$

Cigarette smoking exacerbates Alzheimer's pathology in transgenic mice and rats, including amyloidogenesis, tau phosphorylation, neuroinflammation, and neurodegeneration. ${ }^{174,175}$ Among humans, initial case-control studies reported that cigarette smoking was associated with a reduced risk of $\mathrm{AD} .{ }^{176-178}$ However, these studies may have been biased because smoking is strongly associated with cardiovascular disease and premature death. ${ }^{179}$ Thus, smokers who survive to old age, when they are at greater risk of $\mathrm{AD}$, may be more resilient to the negative effects of smoking and aging-related diseases. Subsequent cohort studies, especially those examining smoking in mid-life, have found that smoking is a risk factor for AD. ${ }^{180-182}$ Cigarette smoking has also been associated with greater regional brain atrophy in cognitively normal individuals. ${ }^{183}$

Some studies suggest that men who smoke are at greater risk of developing AD compared to women who smoke, ${ }^{180,184}$ whereas other studies did not show a sex difference. ${ }^{181}$ Traditionally, men have had a higher prevalence of smoking because it was more socially acceptable for men to smoke. It wasn't until the 1920s and 1930s that more women began to smoke. However, smoking among women was still less than in men. In $1965,51.9 \%$ of men versus $33.9 \%$ of women smoked. ${ }^{185}$ In recent years, the gender gap has been narrowing such that in $2009,23.5 \%$ of men and $17.9 \%$ of women were current smokers. The differential changes in smoking by gender may impact the subsequent incidence rate of $\mathrm{AD}$ among women and men.

\section{Conclusion}

With the aging of the baby boomer generation, the prevalence of AD is reaching an epidemic size. By 2050, 14-16 million Americans will be diagnosed with the disease. Many more individuals will provide either formal or informal care for AD patients. There is currently no cure for this devastating disease. Current approved medications are symptomatic, and do not modify the underlying disease pathology. Although randomized clinical trials of medications to reduce amyloid and other targets are ongoing, a push towards understanding the factors associated with the risk and progression of $\mathrm{AD}$ is critical to identify possible preventive measures and potential new treatment targets. Future clinical trials of new therapies for AD should consider a deliberate stratification 
by sex, and should have adequate sample size to test for a therapeutic effect in men and women separately. A drug may have efficacy in only one sex, or the effect may be stronger in one sex.

A sex-specific or gender-specific focus in AD research is still not mainstream. However, as described in this review, the prevalence and incidence of $\mathrm{AD}$, and brain structure and function, vary by sex and gender. There are also clear sex- and gender-specific risk factors for AD. Ignoring these differences will impede research and treatments. Further, this information is critical for predicting the future disease burden. For example, at the beginning of this century, men had higher education and occupational attainment. However, currently women, on average, have higher educational attainment than men. It is important to study these historical, social, and cultural trends to determine their impact on the future prevalence and incidence of AD. Understanding these sex differences and gender differences will help to define individualized treatment and preventive interventions for $\mathrm{AD}$.

\section{Acknowledgment}

This work was supported in part by P50 AG44170 and U01 AG006786. Mayo Clinic is a National Institutes of Health-designed Specialized Center of Research on Sex Differences.

\section{Disclosure}

The authors report no conflicts of interest in this work.

\section{References}

1. Reitz C, Brayne C, Mayeux R. Epidemiology of Alzheimer disease. Nat Rev Neurol. 2011;7(3):137-152.

2. Thies W, Bleiler L. 2013 Alzheimer's disease facts and figures. Alzheimer's Dement. 2013;9(2):208-245.

3. Hebert LE, Weuve J, Scherr PA, Evans DA. Alzheimer disease in the United States (2010-2050) estimated using the 2010 census. Neurology. 2013;80(19):1778-1783.

4. Hebert LE, Scherr PA, Bienias JL, Bennett DA, Evans DA. Alzheimer disease in the US population: prevalence estimates using the 2000 census. Arch Neurol. 2003;60(8):1119-1122.

5. Petersen RC. Clinical practice. Mild cognitive impairment. $N$ Engl J Med. 2011;364(23):2227-2234.

6. Petersen RC, Roberts RO, Knopman DS, et al. Prevalence of mild cognitive impairment is higher in men: the Mayo Clinic Study of Aging. Neurology. 2010;75(10):889-897.

7. Committee on Understanding the Biology of Sex and Gender Differences, Board on Health Sciences Policy, Institute of Medicine. Exploring the Biological Contributions to Human Health: Does Sex Matter? Wizemann TM, Pardue ML, editors. Washington, DC: National Academy Press; 2001.

8. Carter CL, Resnick EM, Mallampalli M, Kalbarczyk A. Sex and gender differences in Alzheimer's disease: recommendations for future research. $J$ Womens Health (Larchmt). 2012;21(10):1018-1023.

9. Vest RS, Pike CJ. Gender, sex steroid hormones, and Alzheimer's disease. Horm Behav. 2013;63(2):301-307.
10. Regitz-Zagrosek V. Sex and Gender Aspects in Clinical Medicine. Oertelt-Prigione $\mathrm{S}$ and Regitz-Zagrosek V, editors. London: SpringerVerlag Limited; 2012.

11. Hickman SE, Howieson DB, Dame A, Sexton G, Kaye J. Longitudinal analysis of the effects of the aging process on neuropsychological test performance in the healthy young-old and oldest-old. Dev Neuropsychol. 2000;17(3):323-337.

12. Nichols ME, Meador KJ, Loring DW, Poon LW, Clayton GM, Martin P. Age-related changes in the neurologic examination of healthy sexagenarians, octogenarians, and centenarians. J Geriatr Psychiatry Neurol. 1994;7(1):1-7.

13. Beeri MS, Schmeidler J, Sano M, et al. Age, gender, and education norms on the CERAD neuropsychological battery in the oldest old. Neurology. 2006;67(6):1006-1010.

14. Proust-Lima C, Amieva H, Letenneur L, Orgogozo JM, Jacqmin-Gadda H, Dartigues JF. Gender and education impact on brain aging: a general cognitive factor approach. Psychol Aging. 2008;23(3):608-620.

15. van Exel E, Gussekloo J, de Craen AJ, et al. Cognitive function in the oldest old: women perform better than men. J Neurol Neurosurg Psychiatry. 2001;71(1):29-32.

16. van Hooren SA, Valentijn AM, Bosma H, Ponds RW, van Boxtel MP, Jolles J. Cognitive functioning in healthy older adults aged 64-81: a cohort study into the effects of age, sex, and education. Neuropsychol Dev Cogn B Aging Neuropsychol Cogn. 2007;14(1):40-54.

17. Wiederholt WC, Cahn D, Butters NM, Salmon DP, Kritz-Silverstein D, Barrett-Connor E. Effects of age, gender and education on selected neuropsychological tests in an elderly community cohort. J Am Geriatr Soc. 1993;41(6):639-647.

18. Barnes LL, Wilson RS, Schneider JA, Bienias JL, Evans DA, Bennett DA. Gender, cognitive decline, and risk of AD in older persons. Neurology. 2003;60(11):1777-1781.

19. Deary IJ, Gow AJ, Pattie A, Starr JM. Cohort profile: the Lothian Birth Cohorts of 1921 and 1936. Int J Epidemiol. 2012;41(6):1576-1584.

20. Carlson NE, Moore MM, Dame A, et al. Trajectories of brain loss in aging and the development of cognitive impairment. Neurology. 2008;70(11):828-833.

21. Grober E, Hall CB, Lipton RB, Zonderman AB, Resnick SM, Kawas C. Memory impairment, executive dysfunction, and intellectual decline in preclinical Alzheimer's disease. J Int Neuropsychol Soc. 2008;14(2):266-278.

22. Howieson DB, Carlson NE, Moore MM, et al. Trajectory of mild cognitive impairment onset. J Int Neuropsychol Soc. 2008;14(2):192-198.

23. Tierney MC, Moineddin R, McDowell I. Prediction of all-cause dementia using neuropsychological tests within 10 and 5 years of diagnosis in a community-based sample. J Alzheimers Dis. 2010;22(4):1231-1240.

24. Bennett DA, Wilson RS, Schneider JA, et al. Natural history of mild cognitive impairment in older persons. Neurology. 2002;59(2): 198-205.

25. Petersen RC. Mild cognitive impairment as a diagnostic entity. J Intern Med. 2004;256(3):183-194.

26. Winblad B, Palmer K, Kivipelto M, et al. Mild cognitive impairmentbeyond controversies, towards a consensus: report of the International Working Group on Mild Cognitive Impairment. J Intern Med. 2004;256(3):240-246.

27. Manly JJ, Tang MX, Schupf N, Stern Y, Vonsattel JP, Mayeux R. Frequency and course of mild cognitive impairment in a multiethnic community. Ann Neurol. 2008;63(4):494-506.

28. Ravaglia G, Forti P, Montesi F, et al. Mild cognitive impairment: epidemiology and dementia risk in an elderly Italian population. $J \mathrm{Am}$ Geriatr Soc. 2008;56(1):51-58.

29. Luck T, Luppa M, Wiese B, et al; AgeCoDe Study Group. Prediction of incident dementia: impact of impairment in instrumental activities of daily living and mild cognitive impairment-results from the German study on ageing, cognition, and dementia in primary care patients. Am J Geriatr Psychiatry. 2012;20(11):943-954.

30. Petersen RC. Conceptual overview. In: Petersen RC, editor. Mild Cognitive Impairment: Aging to Alzheimer's Disease. New York, NY: Oxford University Press; 2003:1-14. 
31. Lopez OL, Jagust WJ, DeKosky ST, et al. Prevalence and classification of mild cognitive impairment in the Cardiovascular Health Study Cognition Study: part 1. Arch Neurol. 2003;60(10): 1385-1389.

32. Plassman BL, Langa KM, Fisher GG, et al. Prevalence of cognitive impairment without dementia in the United States. Ann Intern Med. 2008;148(6):427-434.

33. Di Carlo A, Lamassa M, Baldereschi M, et al. CIND and MCI in the Italian elderly: frequency, vascular risk factors, progression to dementia. Neurology. 2007;68(22):1909-1916.

34. Ganguli M, Chang CC, Snitz BE, Saxton JA, Vanderbilt J, Lee CW. Prevalence of mild cognitive impairment by multiple classifications: the Monongahela-Youghiogheny Healthy Aging Team (MYHAT) project. Am J Geriatr Psychiatry. 2010;18(8):674-683.

35. Ganguli M, Dodge HH, Shen C, DeKosky ST. Mild cognitive impairment, amnestic type: an epidemiologic study. Neurology. 2004;63(1): $115-121$

36. Koivisto K, Reinikainen KJ, Hänninen T, et al. Prevalence of ageassociated memory impairment in a randomly selected population from eastern Finland. Neurology. 1995;45(4):741-747.

37. Larrieu S, Letenneur L, Orgogozo JM, et al. Incidence and outcome of mild cognitive impairment in a population-based prospective cohort. Neurology. 2002;59(10):1594-1599.

38. Kivipelto M, Helkala EL, Hänninen T, et al. Midlife vascular risk factors and late-life mild cognitive impairment: a population-based study. Neurology. 2001;56(12):1683-1689.

39. Hänninen T, Hallikainen M, Tuomainen S, Vanhanen M, Soininen H. Prevalence of mild cognitive impairment: a population-based study in elderly subjects. Acta Neurol Scand. 2002;106(3):148-154.

40. Solfrizzi V, Panza F, Colacicco AM, et al; Italian Longitudinal Study on Aging Working Group. Vascular risk factors, incidence of MCI, and rates of progression to dementia. Neurology. 2004;63(10): 1882-1891.

41. Luck T, Luppa M, Briel S, et al. Mild cognitive impairment: incidence and risk factors: results of the Leipzig Longitudinal Study of the Aged. J Am Geriatr Soc. 2010;58(10):1903-1910.

42. Roberts RO, Geda YE, Knopman DS, et al. The incidence of MCI differs by subtype and is higher in men: the Mayo Clinic Study of Aging. Neurology. 2012;78(5):342-351.

43. Caracciolo B, Palmer K, Monastero R, Winblad B, Bäckman L, Fratiglioni L. Occurrence of cognitive impairment and dementia in the community: a 9-year-long prospective study. Neurology. 2008; 70(19 Pt 2):1778-1785.

44. Plassman BL, Langa KM, Fisher GG, et al. Prevalence of dementia in the United States: the aging, demographics, and memory study. Neuroepidemiology. 2007;29(1-2):125-132.

45. Seshadri S, Wolf PA, Beiser A, et al. Lifetime risk of dementia and Alzheimer's disease. The impact of mortality on risk estimates in the Framingham Study. Neurology. 1997;49(6):1498-1504.

46. Rocca WA, Cha RH, Waring SC, Kokmen E. Incidence of dementia and Alzheimer's disease: a reanalysis of data from Rochester, Minnesota, 1975-1984. Am J Epidemiol. 1998;148(1):51-62.

47. Bachman DL, Wolf PA, Linn RT, et al. Incidence of dementia and probable Alzheimer's disease in a general population: the Framingham Study. Neurology. 1993;43(3 Pt 1):515-519.

48. Ganguli M, Dodge HH, Chen P, Belle S, DeKosky ST. Ten-year incidence of dementia in a rural elderly US community population: the MoVIES Project. Neurology. 2000;54(5):1109-1116.

49. Kawas C, Gray S, Brookmeyer R, Fozard J, Zonderman A. Age-specific incidence rates of Alzheimer's disease: the Baltimore Longitudinal Study of Aging. Neurology. 2000;54(11):2072-2077.

50. Hebert LE, Scherr PA, McCann JJ, Beckett LA, Evans DA. Is the risk of developing Alzheimer's disease greater for women than for men? Am J Epidemiol. 2001;153(2):132-136.

51. Kukull WA, Higdon R, Bowen JD, et al. Dementia and Alzheimer disease incidence: a prospective cohort study. Arch Neurol. 2002;59(11): 1737-1746.
52. Edland SD, Rocca WA, Petersen RC, Cha RH, Kokmen E. Dementia and Alzheimer disease incidence rates do not vary by sex in Rochester, Minn. Arch Neurol. 2002;59(10):1589-1593.

53. Miech RA, Breitner JC, Zandi PP, Khachaturian AS, Anthony JC, Mayer L. Incidence of AD may decline in the early 90 s for men, later for women: the Cache County study. Neurology. 2002;58(2):209-218.

54. Roberts RO, Knopman DS, Mielke MM, et al. Higher risk of progression to dementia in mild cognitive impairment cases who revert to normal. Neurology. In press 2013.

55. Fratiglioni L, Viitanen M, von Strauss E, Tontodonati V, Herlitz A, Winblad B. Very old women at highest risk of dementia and Alzheimer's disease: incidence data from the Kungsholmen Project, Stockholm. Neurology. 1997;48(1):132-138.

56. Ott A, Breteler MM, van Harskamp F, Stijnen T, Hofman A. Incidence and risk of dementia. The Rotterdam Study. Am J Epidemiol. 1998;147(6):574-580.

57. Letenneur L, Gilleron V, Commenges D, Helmer C, Orgogozo JM, Dartigues JF. Are sex and educational level independent predictors of dementia and Alzheimer's disease? Incidence data from the PAQUID project. J Neurol Neurosurg Psychiatry. 1999;66(2):177-183.

58. Andersen K, Launer LJ, Dewey ME, et al. Gender differences in the incidence of $\mathrm{AD}$ and vascular dementia: the EURODEM Studies. EURODEM Incidence Research Group. Neurology. 1999;53(9): 1992-1997.

59. Ruitenberg A, Ott A, van Swieten JC, Hofman A, Breteler MM. Incidence of dementia: does gender make a difference? Neurobiol Aging. 2001;22(4):575-580.

60. Yoshitake T, Kiyohara Y, Kato I, et al. Incidence and risk factors of vascular dementia and Alzheimer's disease in a defined elderly Japanese population: the Hisayama Study. Neurology. 1995;45(6):1161-1168.

61. Liu CK, Lai CL, Tai CT, Lin RT, Yen YY, Howng SL. Incidence and subtypes of dementia in southern Taiwan: impact of socio-demographic factors. Neurology. 1998;50(6):1572-1579.

62. Gao S, Hendrie HC, Hall KS, Hui S. The relationships between age, sex, and the incidence of dementia and Alzheimer disease: a meta-analysis. Arch Gen Psychiatry. 1998;55(9):809-815.

63. Agüero-Torres H, Fratiglioni L, Guo Z, Viitanen M, Winblad B. Prognostic factors in very old demented adults: a seven-year follow-up from a population-based survey in Stockholm. J Am Geriatr Soc. 1998;46(4):444-452.

64. Tschanz JT, Corcoran CD, Schwartz S, et al. Progression of cognitive, functional, and neuropsychiatric symptom domains in a population cohort with Alzheimer dementia: the Cache County Dementia Progression study. Am J Geriatr Psychiatry. 2011;19(6):532-542.

65. Katzman R, Terry R, DeTeresa R, et al. Clinical, pathological, and neurochemical changes in dementia: a subgroup with preserved mental status and numerous neocortical plaques. Ann Neurol. 1988;23(2):138-144.

66. Giedd JN, Raznahan A, Mills KL, Lenroot RK. Review: magnetic resonance imaging of male/female differences in human adolescent brain anatomy. Biol Sex Differ. 2012;3(1):19.

67. Barnes LL, Wilson RS, Bienias JL, Schneider JA, Evans DA, Bennett DA. Sex differences in the clinical manifestations of Alzheimer disease pathology. Arch Gen Psychiatry. 2005;62(6):685-691.

68. Coffey CE, Lucke JF, Saxton JA, et al. Sex differences in brain aging: a quantitative magnetic resonance imaging study. Arch Neurol. 1998;55(2):169-179.

69. Oguro H, Okada K, Yamaguchi S, Kobayashi S. Sex differences in morphology of the brain stem and cerebellum with normal ageing. Neuroradiology. 1998;40(12):788-792.

70. Gur RC, Gunning-Dixon FM, Turetsky BI, Bilker WB, Gur RE. Brain region and sex differences in age association with brain volume: a quantitative MRI study of healthy young adults. Am J Geriatr Psychiatry. 2002;10(1):72-80.

71. Pfefferbaum A, Rohlfing T, Rosenbloom MJ, Chu W, Colrain IM, Sullivan EV. Variation in longitudinal trajectories of regional brain volumes of healthy men and women (ages 10 to 85 years) measured with atlas-based parcellation of MRI. Neuroimage. 2013;65:176-193. 
72. Skup M, Zhu H, Wang Y, et al; Alzheimer's Disease Neuroimaging Initiative. Sex differences in grey matter atrophy patterns among AD and aMCI patients: results from ADNI. Neuroimage. 2011;56(3):890-906.

73. Luders E, Gaser C, Narr KL, Toga AW. Why sex matters: brain size independent differences in gray matter distributions between men and women. J Neurosci. 2009;29(45):14265-14270.

74. Good CD, Johnsrude IS, Ashburner J, Henson RN, Friston KJ, Frackowiak RS. A voxel-based morphometric study of ageing in 465 normal adult human brains. Neuroimage. 2001;14(1 Pt 1):21-36.

75. Giedd JN, Castellanos FX, Rajapakse JC, Vaituzis AC, Rapoport JL. Sexual dimorphism of the developing human brain. Prog Neuropsychopharmacol Biol Psychiatry. 1997;21(8):1185-1201.

76. Cosgrove KP, Mazure CM, Staley JK. Evolving knowledge of sex differences in brain structure, function, and chemistry. Biol Psychiatry. 2007;62(8):847-855.

77. Witte AV, Savli M, Holik A, Kasper S, Lanzenberger R. Regional sex differences in grey matter volume are associated with sex hormones in the young adult human brain. Neuroimage. 2010;49(2):1205-1212.

78. van Amelsvoort T, Compton J, Murphy D. In vivo assessment of the effects of estrogen on human brain. Trends Endocrinol Metab. 2001;12(6):273-276.

79. Lentini E, Kasahara M, Arver S, Savic I. Sex differences in the human brain and the impact of sex chromosomes and sex hormones. Cereb Cortex. 2013;23(10):2322-2336.

80. Biswal BB, Mennes M, Zuo XN, et al. Toward discovery science of human brain function. Proc Natl Acad Sci U S A. 2010;107(10):4734-4739.

81. Hsieh TC, Lin WY, Ding HJ, et al. Sex- and age-related differences in brain FDG metabolism of healthy adults: an SPM analysis. J Neuroimaging. 2012;22(1):21-27.

82. Gur RC, Mozley LH, Mozley PD, et al. Sex differences in regional cerebral glucose metabolism during a resting state. Science. 1995; 267(5197):528-531.

83. Perneczky R, Drzezga A, Diehl-Schmid J, Li Y, Kurz A. Gender differences in brain reserve: an (18)F-FDG PET study in Alzheimer's disease. J Neurol. 2007;254(10):1395-1400.

84. Perneczky R, Diehl-Schmid J, Förstl H, Drzezga A, Kurz A. Male gender is associated with greater cerebral hypometabolism in frontotemporal dementia: evidence for sex-related cognitive reserve. Int $J$ Geriatr Psychiatry. 2007;22(11):1135-1140.

85. Buckner RL, Snyder AZ, Shannon BJ, et al. Molecular, structural, and functional characterization of Alzheimer's disease: evidence for a relationship between default activity, amyloid, and memory. $J$ Neurosci. 2005;25(34):7709-7717.

86. Strittmatter WJ, Saunders AM, Schmechel D, et al. Apolipoprotein E: high-avidity binding to beta-amyloid and increased frequency of type 4 allele in late-onset familial Alzheimer disease. Proc Natl Acad Sci U S A. 1993;90(5):1977-1981.

87. Corder EH, Saunders AM, Strittmatter WJ, et al. Gene dose of apolipoprotein E type 4 allele and the risk of Alzheimer's disease in late onset families. Science. 1993;261(5123):921-923.

88. Bertram L, Tanzi RE. Thirty years of Alzheimer's disease genetics: the implications of systematic meta-analyses. Nat Rev Neurosci. 2008;9(10):768-778.

89. Meyer MR, Tschanz JT, Norton MC, et al. APOE genotype predicts when - not whether - one is predisposed to develop Alzheimer disease. Nat Genet. 1998;19(4):321-322.

90. Farrer LA, Cupples LA, Haines JL, et al. Effects of age, sex, and ethnicity on the association between apolipoprotein E genotype and Alzheimer disease. A meta-analysis. APOE and Alzheimer Disease Meta Analysis Consortium. JAMA. 1997;278(16):1349-1356.

91. Payami H, Zareparsi S, Montee KR, et al. Gender difference in apolipoprotein E-associated risk for familial Alzheimer disease: a possible clue to the higher incidence of Alzheimer disease in women. Am J Hum Genet. 1996;58(4):803-811.

92. Bretsky PM, Buckwalter JG, Seeman TE, et al. Evidence for an interaction between apolipoprotein E genotype, gender, and Alzheimer disease. Alzheimer Dis Assoc Disord. 1999;13(4):216-221.
93. Fleisher A, Grundman M, Jack CR Jr, et al; Alzheimer's Disease Cooperative Study. Sex, apolipoprotein E epsilon 4 status, and hippocampal volume in mild cognitive impairment. Arch Neurol. 2005;62(6):953-957.

94. Liu Y, Paajanen T, Westman E, et al; AddNeuroMed Consortium. Effect of APOE $\varepsilon 4$ allele on cortical thicknesses and volumes: the AddNeuroMed study. J Alzheimers Dis. 2010;21(3):947-966.

95. Damoiseaux JS, Seeley WW, Zhou J, et al; Alzheimer's Disease Neuroimaging Initiative. Gender modulates the APOE $\varepsilon 4$ effect in healthy older adults: convergent evidence from functional brain connectivity and spinal fluid tau levels. J Neurosci. 2012;32(24):8254-8262.

96. Corder EH, Ghebremedhin E, Taylor MG, Thal DR, Ohm TG, Braak H. The biphasic relationship between regional brain senile plaque and neurofibrillary tangle distributions: modification by age, sex, and APOE polymorphism. Ann NY Acad Sci. 2004;1019:24-28.

97. Fukumoto N, Fujii T, Combarros O, et al. Sexually dimorphic effect of the Val66Met polymorphism of BDNF on susceptibility to Alzheimer's disease: new data and meta-analysis. Am J Med Genet $B$ Neuropsychiatr Genet. 2010;153B(1):235-242.

98. Sohrabji F, Miranda RC, Toran-Allerand CD. Identification of a putative estrogen response element in the gene encoding brainderived neurotrophic factor. Proc Natl Acad Sci U S A. 1995;92(24): 11110-11114.

99. Zou F, Gopalraj RK, Lok J, et al. Sex-dependent association of a common low-density lipoprotein receptor polymorphism with RNA splicing efficiency in the brain and Alzheimer's disease. Hum Mol Genet. 2008;17(7):929-935.

100. Albayrak O, Tirniceriu A, Riemenschneider M, Kurz A, Scherag A, Egensperger R. The cathepsin D $(224 \mathrm{C} / \mathrm{T})$ polymorphism confers an increased risk to develop Alzheimer's disease in men. J Gerontol A Biol Sci Med Sci. 2010;65(3):219-224.

101. Hamilton G, Proitsi P, Jehu L, et al. Candidate gene association study of insulin signaling genes and Alzheimer's disease: evidence for SOS2, PCK1, and PPARgamma as susceptibility loci. Am J Med Genet B Neuropsychiatr Genet. 2007;144B(4):508-516.

102. Sundar PD, Feingold E, Minster RL, DeKosky ST, Kamboh MI. Gender-specific association of ATP-binding cassette transporter 1 (ABCA1) polymorphisms with the risk of late-onset Alzheimer's disease. Neurobiol Aging. 2007;28(6):856-862.

103. Srivastava RA. Estrogen-induced regulation of the ATP-binding cassette transporter A1 (ABCA1) in mice: a possible mechanism of atheroprotection by estrogen. Mol Cell Biochem. 2002;240(1-2):67-73.

104. Nugent BM, Tobet SA, Lara HE, et al. Hormonal programming across the lifespan. Horm Metab Res. 2012;44(8):577-586.

105. Morrison JH, Brinton RD, Schmidt PJ, Gore AC. Estrogen, menopause, and the aging brain: how basic neuroscience can inform hormone therapy in women. $J$ Neurosci. 2006;26(41):10332-10348.

106. Rocca WA, Grossardt BR, Shuster LT. Oophorectomy, menopause, estrogen treatment, and cognitive aging: clinical evidence for a window of opportunity. Brain Res. 2011;1379:188-198.

107. Feldman HA, Longcope C, Derby CA, et al. Age trends in the level of serum testosterone and other hormones in middle-aged men: longitudinal results from the Massachusetts male aging study. $J$ Clin Endocrinol Metab. 2002;87(2):589-598.

108. Murphy DD, Segal M. Regulation of dendritic spine density in cultured rat hippocampal neurons by steroid hormones. J Neurosci. 1996;16(13):4059-4068.

109. Aenlle KK, Kumar A, Cui L, Jackson TC, Foster TC. Estrogen effects on cognition and hippocampal transcription in middle-aged mice. Neurobiol Aging. 2009;30(6):932-945.

110. Han X, Aenlle KK, Bean LA, et al. Role of estrogen receptor $\alpha$ and $\beta$ in preserving hippocampal function during aging. J Neurosci. 2013;33(6):2671-2683.

111. Wang Q, Santizo R, Baughman VL, Pelligrino DA, Iadecola C. Estrogen provides neuroprotection in transient forebrain ischemia through perfusion-independent mechanisms in rats. Stroke. 1999;30(3):630-637. 
112. Gibbs RB. Estrogen and nerve growth factor-related systems in brain. Effects on basal forebrain cholinergic neurons and implications for learning and memory processes and aging. Ann N Y Acad Sci. 1994;743:165-196; discussion 197-169.

113. Gibbs RB, Aggarwal P. Estrogen and basal forebrain cholinergic neurons: implications for brain aging and Alzheimer's disease-related cognitive decline. Horm Behav. 1998;34(2):98-111.

114. Nilsen J, Chen S, Irwin RW, Iwamoto S, Brinton RD. Estrogen protects neuronal cells from amyloid beta-induced apoptosis via regulation of mitochondrial proteins and function. BMC Neurosci. 2006;7:74.

115. Jaffe AB, Toran-Allerand CD, Greengard P, Gandy SE. Estrogen regulates metabolism of Alzheimer amyloid beta precursor protein. J Biol Chem. 1994;269(18):13065-13068.

116. Yao J, Brinton RD. Estrogen regulation of mitochondrial bioenergetics: implications for prevention of Alzheimer's disease. Adv Pharmacol. 2012;64:327-371.

117. Waring SC, Rocca WA, Petersen RC, O’Brien PC, Tangalos EG, Kokmen E. Postmenopausal estrogen replacement therapy and risk of AD: a population-based study. Neurology. 1999;52(5):965-970.

118. LeBlanc ES, Janowsky J, Chan BK, Nelson HD. Hormone replacement therapy and cognition: systematic review and meta-analysis. JAMA. 2001;285(11):1489-1499.

119. Zandi PP, Carlson MC, Plassman BL, et al; Cache County Memory Study Investigators. Hormone replacement therapy and incidence of Alzheimer disease in older women: the Cache County Study. JAMA. 2002;288(17):2123-2129.

120. Henderson VW, Benke KS, Green RC, Cupples LA, Farrer LA; MIRAGE Study Group. Postmenopausal hormone therapy and Alzheimer's disease risk: interaction with age. J Neurol Neurosurg Psychiatry. 2005;76(1):103-105.

121. Whitmer RA, Quesenberry CP, Zhou J, Yaffe K. Timing of hormone therapy and dementia: the critical window theory revisited. Ann Neurol. 2011;69(1):163-169.

122. Shao H, Breitner JC, Whitmer RA, et al; Cache County Investigators. Hormone therapy and Alzheimer disease dementia: new findings from the Cache County Study. Neurology. 2012;79(18):1846-1852.

123. Rocca WA, Bower JH, Maraganore DM, et al. Increased risk of cognitive impairment or dementia in women who underwent oophorectomy before menopause. Neurology. 2007;69(11):1074-1083.

124. Shumaker SA, Legault C, Kuller L, et al; Women's Health Initiative Memory Study. Conjugated equine estrogens and incidence of probable dementia and mild cognitive impairment in postmenopausal women: Women's Health Initiative Memory Study. JAMA. 2004;291(24): 2947-2958.

125. Rocca WA, Grossardt BR, Shuster LT. Oophorectomy, menopause, estrogen, and cognitive aging: the timing hypothesis. Neurodegener Dis. 2010;7(1-3):163-166.

126. Zhang QG, Han D, Wang RM, et al. C terminus of Hsc70interacting protein (CHIP)-mediated degradation of hippocampal estrogen receptor-alpha and the critical period hypothesis of estrogen neuroprotection. Proc Natl Acad Sci U S A. 2011;108(35): E617-E624.

127. Brinton RD. The healthy cell bias of estrogen action: mitochondrial bioenergetics and neurological implications. Trends Neurosci. 2008;31(10):529-537.

128. Kreiger N. Epidemiology and the People's Health: Theory and Context. New York: Oxford University Press; 2011.

129. Whalley LJ, Deary IJ, Appleton CL, Starr JM. Cognitive reserve and the neurobiology of cognitive aging. Ageing Res Rev. 2004;3(4): 369-382.

130. Stern Y. Cognitive reserve. Neuropsychologia. 2009;47(10): 2015-2028

131. Vemuri P, Lesnick TG, Przybelski SA, et al. Effect of lifestyle activities on Alzheimer disease biomarkers and cognition. Ann Neurol. 2012;72(5):730-738.

132. Stern Y. Cognitive reserve in ageing and Alzheimer's disease. Lancet Neurol. 2012;11(11):1006-1012.
133. Katzman R. Education and the prevalence of dementia and Alzheimer's disease. Neurology. 1993;43(1):13-20.

134. Fratiglioni L, Grut M, Forsell Y, et al. Prevalence of Alzheimer's disease and other dementias in an elderly urban population: relationship with age, sex, and education. Neurology. 1991;41(12):1886-1892.

135. Zhang MY, Katzman R, Salmon D, et al. The prevalence of dementia and Alzheimer's disease in Shanghai, China: impact of age, gender, and education. Ann Neurol. 1990;27(4):428-437.

136. Bonaiuto S, Rocca WA, Lippi A, et al. Education and occupation as risk factors for dementia: a population-based case-control study. Neuroepidemiology. 1995;14(3):101-109.

137. Mortimer JA, Graves AB. Education and other socioeconomic determinants of dementia and Alzheimer's disease. Neurology. 1993;43(8, Suppl 4):S39-S44.

138. Karp A, Kåreholt I, Qiu C, Bellander T, Winblad B, Fratiglioni L. Relation of education and occupation-based socioeconomic status to incident Alzheimer's disease. Am J Epidemiol. 2004;159(2):175-183.

139. Bickel H, Cooper B. Incidence and relative risk of dementia in an urban elderly population: findings of a prospective field study. Psychol Med. 1994;24(1):179-192.

140. Stern Y, Gurland B, Tatemichi TK, Tang MX, Wilder D, Mayeux R. Influence of education and occupation on the incidence of Alzheimer's disease. JAMA. 1994;271(13):1004-1010.

141. Roe CM, Xiong C, Miller JP, Morris JC. Education and Alzheimer disease without dementia: support for the cognitive reserve hypothesis. Neurology. 2007;68(3):223-228.

142. Crowe M, Andel R, Pedersen NL, Johansson B, Gatz M. Does participation in leisure activities lead to reduced risk of Alzheimer's disease? A prospective study of Swedish twins. J Gerontol B Psychol Sci Soc Sci. 2003;58(5):P249-P255.

143. Fabrigoule C. Do leisure activities protect against Alzheimer's disease? Lancet Neurol. 2002;1(1):11.

144. Gale CR, Cooper R, Craig L, et al. Cognitive function in childhood and lifetime cognitive change in relation to mental wellbeing in four cohorts of older people. PLOS ONE. 2012;7(9):e44860.

145. Whalley LJ, Starr JM, Athawes R, Hunter D, Pattie A, Deary IJ. Childhood mental ability and dementia. Neurology. 2000;55(10): 1455-1459.

146. Whalley LJ, Deary IJ. Longitudinal cohort study of childhood IQ and survival up to age 76. BMJ. 2001;322(7290):819.

147. Scarmeas N, Zarahn E, Anderson KE, et al. Association of life activities with cerebral blood flow in Alzheimer disease: implications for the cognitive reserve hypothesis. Arch Neurol. 2003;60(3):359-365.

148. Garibotto V, Borroni B, Kalbe E, et al. Education and occupation as proxies for reserve in aMCI converters and AD: FDG-PET evidence. Neurology. 2008;71(17):1342-1349.

149. Kemppainen NM, Aalto S, Karrasch M, et al. Cognitive reserve hypothesis: Pittsburgh Compound B and fluorodeoxyglucose positron emission tomography in relation to education in mild Alzheimer's disease. Ann Neurol. 2008;63(1):112-118.

150. Roe CM, Mintun MA, D’Angelo G, Xiong C, Grant EA, Morris JC. Alzheimer disease and cognitive reserve: variation of education effect with carbon 11-labeled Pittsburgh Compound B uptake. Arch Neurol. 2008;65(11):1467-1471.

151. Schneider AL, Sharrett AR, Patel MD, et al. Education and cognitive change over 15 years: the atherosclerosis risk in communities study. J Am Geriatr Soc. 2012;60(10):1847-1853.

152. Gerstorf D, Ram N, Hoppmann C, Willis SL, Schaie KW. Cohort differences in cognitive aging and terminal decline in the Seattle Longitudinal Study. Dev Psychol. 2011;47(4):1026-1041.

153. Schaie KW, Willis SL. The Seattle Longitudinal Study of Adult Cognitive Development. ISSBD Bull. 2010;57(1):24-29.

154. Ryan CL, Siebens J. Educational Attainment in the United States: 2009. Current Population Reports. Washington, DC: US Department of Commerce, US Census Bureau; 2012. Available from: http:// www.census.gov/prod/2012pubs/p20-566.pdf. Accessed August 17, 2013. 
155. Verhoef MJ, Love EJ, Rose MS. Women's social roles and their exercise participation. Women Health. 1992;19(4):15-29.

156. Geda YE, Roberts RO, Knopman DS, et al. Physical exercise, aging, and mild cognitive impairment: a population-based study. Arch Neurol. 2010;67(1):80-86.

157. Hamer M, Chida Y. Physical activity and risk of neurodegenerative disease: a systematic review of prospective evidence. Psychol Med. 2009;39(1):3-11.

158. Middleton LE, Barnes DE, Lui LY, Yaffe K. Physical activity over the life course and its association with cognitive performance and impairment in old age. J Am Geriatr Soc. 2010;58(7):1322-1326.

159. Liu R, Sui X, Laditka JN, et al. Cardiorespiratory fitness as a predictor of dementia mortality in men and women. Med Sci Sports Exerc. 2012;44(2):253-259.

160. Buchman AS, Boyle PA, Yu L, Shah RC, Wilson RS, Bennett DA. Total daily physical activity and the risk of $\mathrm{AD}$ and cognitive decline in older adults. Neurology. 2012;78(17):1323-1329.

161. Pitkälä KH, Pöysti MM, Laakkonen ML, et al. Effects of the Finnish Alzheimer disease exercise trial (FINALEX): a randomized controlled trial. JAMA Intern Med. 2013;173(10):894-901.

162. Nomaguchi KM, Bianchi SM. Exercise time: gender differences in the effects of marriage, parenthood, and employment. J Marriage Fam. 2004;66(2):413-430

163. Hogervorst E, Clifford A, Stock J, Xin X, Bandelow S. Exercise to prevent cognitive decline and Alzheimer's disease: for whom, when, what, and (most importantly) how much? J Alzheimers Dis Park. 2012;2(3):e117.

164. Clifford A, Bandelow S, Hogervorst E. The effects of physical exercise on cognitive function in the elderly: A review. In: Gariépy Q, Ménard R, editors. Handbook of Cognitive Aging: Causes, Processes and Effects. New York: Nova Science Publishers; 2010:109-150.

165. Fallah N, Mitnitski A, Middleton L, Rockwood K. Modeling the impact of sex on how exercise is associated with cognitive changes and death in older Canadians. Neuroepidemiology. 2009;33(1):47-54.

166. Sibley BA, Etnier JL. The relationship between physical activity and cognition in children: a meta-analysis. Pediatr Exerc Sci. 2003;15(3): 243-256.

167. Scarmeas N, Stern Y. Cognitive reserve and lifestyle. J Clin Exp Neuropsychol. 2003;25(5):625-633.

168. McGavock J, Sellers E, Dean H. Physical activity for the prevention and management of youth-onset type 2 diabetes mellitus: focus on cardiovascular complications. Diab Vasc Dis Res. 2007;4(4):305-310.

169. Luchsinger JA. Adiposity, hyperinsulinemia, diabetes and Alzheimer's disease: an epidemiological perspective. Eur J Pharmacol. 2008; 585(1):119-129.

170. Rezvani AH, Levin ED. Cognitive effects of nicotine. Biol Psychiatry. 2001;49(3):258-267.

171. Wilson AL, Langley LK, Monley J, et al. Nicotine patches in Alzheimer's disease: pilot study on learning, memory, and safety. Pharmacol Biochem Behav. 1995;51(2-3):509-514.
172. White HK, Levin ED. Four-week nicotine skin patch treatment effects on cognitive performance in Alzheimer's disease. Psychopharmacology (Berl). 1999;143(2):158-165.

173. Hagger-Johnson G, Sabia S, Brunner EJ, et al. Combined impact of smoking and heavy alcohol use on cognitive decline in early old age: Whitehall II prospective cohort study. Br J Psychiatry. 2013;203(2): $120-125$.

174. Moreno-Gonzalez I, Estrada LD, Sanchez-Mejias E, Soto C. Smoking exacerbates amyloid pathology in a mouse model of Alzheimer's disease. Nat Commun. 2013;4:1495.

175. Ho YS, Yang X, Yeung SC, et al. Cigarette smoking accelerated brain aging and induced pre-Alzheimer-like neuropathology in rats. PLoS ONE. 2012;7(5):e36752.

176. Katzman R, Aronson M, Fuld P, et al. Development of dementing illnesses in an 80-year-old volunteer cohort. Ann Neurol. 1989;25(4): $317-324$.

177. Graves AB, van Duijn CM, Chandra V, et al. Alcohol and tobacco consumption as risk factors for Alzheimer's disease: a collaborative re-analysis of case-control studies. EURODEM Risk Factors Research Group. Int J Epidemiol. 1991;20 Suppl 2:S48-S57.

178. Lee PN. Smoking and Alzheimer's disease: a review of the epidemiological evidence. Neuroepidemiology. 1994;13(4):131-144.

179. Doll R, Peto R, Wheatley K, Gray R, Sutherland I. Mortality in relation to smoking: 40 years' observations on male British doctors. BMJ. 1994;309(6959):901-911.

180. Ott A, Slooter AJ, Hofman A, et al. Smoking and risk of dementia and Alzheimer's disease in a population-based cohort study: the Rotterdam Study. Lancet. 1998;351(9119):1840-1843.

181. Rusanen M, Kivipelto M, Quesenberry CP Jr, Zhou J, Whitmer RA. Heavy smoking in midlife and long-term risk of Alzheimer disease and vascular dementia. Arch Intern Med. 2011;171(4):333-339.

182. Tyas SL, White LR, Petrovitch H, et al. Mid-life smoking and latelife dementia: the Honolulu-Asia Aging Study. Neurobiol Aging. 2003;24(4):589-596.

183. Durazzo TC, Insel PS, Weiner MW; Alzheimer Disease Neuroimaging Initiative. Greater regional brain atrophy rate in healthy elderly subjects with a history of cigarette smoking. Alzheimers Dement. 2012;8(6):513-519.

184. Launer LJ, Andersen K, Dewey ME, et al. Rates and risk factors for dementia and Alzheimer's disease: results from EURODEM pooled analyses. EURODEM Incidence Research Group and Work Groups. European Studies of Dementia. Neurology. 1999;52(1):78-84.

185. American Lung Association. Research and Program Services, Epidemiology and Statistics Unit. Trends in tobacco use. 2011. PDF available from http://www.lung.org/finding-cures/our-research/trendreports/Tobacco-Trend-Report.pdf. Accessed December 17, 2013.
Clinical Epidemiology

\section{Publish your work in this journal}

Clinical Epidemiology is an international, peer-reviewed, open access journal focusing on disease and drug epidemiology, identification of risk factors and screening procedures to develop optimal preventative initiatives and programs. Specific topics include: diagnosis, prognosis, treatment, screening, prevention, risk factor modification, systematic
Dovepress

reviews, risk \& safety of medical interventions, epidemiology \& biostatical methods, evaluation of guidelines, translational medicine, health policies \& economic evaluations. The manuscript management system is completely online and includes a very quick and fair peer-review system, which is all easy to use. 